\title{
ARQUITETURA HOSPITALAR: HISTÓRIA, EVOLUÇÃO E NOVAS VISÕES
}

\author{
Elza Maria Alves Costeira \\ Arquiteta M. Sc e doutoranda PROARQ/FAU/UFRJ; \\ Pesquisadora do Departamento de Patrimônio Histórico da FIOCRUZ; \\ Pesquisadora do Observatório Urbano do Estado do Rio de Janeiro- OUERJ/UERJ \\ $\triangle$ ecosteira@uol.com.br
}

Nas últimas décadas surgiram novos conceitos para o desenho de hospitais que procuram trazer para o seus espaços os valores que os pacientes encontram em suas casas, ou seja: os projetos arquitetônicos devem incorporar ao edifício a visão do paciente e suas representações cotidianas. Esses conceitos propõem também a integração dos ambientes de saúde com o espaço exterior e incorporam nos setores de diagnóstico e tratamento uma série de premissas que são consideradas como promotoras da cura. As pesquisas atuais sobre tempo de permanência e a qualidade da atenção destinada aos clientes apontam para a ênfase da humanização destes ambientes, no sentido de amenizar o sofrimento e a angustia durante a internação, agregando práticas de convivência familiar e de personalização aos espaços, envolvendo equipes de profissionais e de familiares nas terapias desenvolvidas para atingir a desejada cura.

No entanto temos que retroceder no tempo para que possamos entender como a importância da Arquitetura de Ambientes de Saúde e desse profissional - o Arquiteto Hospitalar - foram sendo estabelecidos, tornando-se cada vez mais fundamentais para a implantação dos novos centros de excelência em atenção à saúde que surgem no nosso país.

Podemos dizer que o aspecto do hospital contemporâneo formatou-se entre os séculos XVII e XVIII, na Europa. O evento citado como determinante para a mudança da velha estrutura hospitalar, com instalações insalubres, abrigando centenas de enfermos agrupados, foi o grande incêndio do Hotel-Dieu, em Paris, em 1772. Como esta era uma instituição que acolhia muitos pacientes, era urgente a sua reconstrução ou a sua substituição. Foi estabelecida uma comissão para avaliar projetos arquitetônicos adequados ao caso, realizando estudos e pesquisas para encontrar uma solução definitiva para o hospital. Esta comissão era composta por nove membros e foi nomeada pela Academia Real de Ciências, a partir dos esforços do Barão de Breteuil, da Casa Real de Luis XVI. Nesta ocasião teve destaque o conjunto de trabalhos do médico Tenon, que analisou diversos hospitais, não só com o intuito 
de descrever a obra arquitetônica, mas, também com um olhar crítico, funcionalista. Ele publicou, em 1788, cinco relatórios reunidos em uma obra de nome "Memoires sur les hôpitaux de Paris".

Com o "projeto" Tenon, triunfa a organização pavilhonar, horizontal, do espaço hospitalar. Com a adoção desta forma, que permitia a ventilação cruzada e uma excelente iluminação natural, Tenon acreditava ter resolvido o que era considerado o maior produtor da insalubridade nos hospitais: a estagnação do ar e a umidade. Ele efetuou também toda uma série de estudos volumétricos para estabelecer a relação entre as dimensões de cada pavilhão de enfermos e o número de leitos das enfermarias, como meio de assegurar o volume mínimo ideal de ar renovado para cada paciente. Tenon estudou também o número ideal de pavimentos para cada pavilhão, estabelecendo em três o número ideal de pavimentos.

Os elementos de importância tecnológica na consolidação deste perfil, no século XIX, foram o desenvolvimento da anestesia, as práticas de assepsia e a disseminação da profissão de enfermeira, laica, neste caso. Durante todo o século XIX surgiu, também, a preocupação com a ventilação e a iluminação naturais nos projetos dos edifícios de saúde, a partir da chamada "teoria dos miasmas", onde a propagação de doenças era atribuída à emanação de eflúvios originários de matéria em decomposição.

A descoberta da transmissão de germes, em 1860, revoluciona a concepção dos projetos hospitalares, isolando as patologias e os doentes em pavilhões específicos. Os trabalhos de Louis Pasteur demonstram a necessidade de combater o contágio e a transmissão de doenças, com a separação de pacientes e a esterilização de utensílios médicos. Estes princípios de isolamento das patologias acarretam uma verdadeira revolução nos projetos de unidades de saúde. A disposição e a composição da arquitetura em pavilhões múltiplos facilitam o desenvolvimento das construções e a integração com o seu espaço de instalação, possibilitando a criação de hospitais do tamanho de quarteirões, e de implantações assemelhadas a pequenas cidades-jardim.

Nesta época a cirurgia se incorporou definitivamente às instituições hospitalares e, ao lado do surgimento da medicina científica, do modelo pavilhonar e da divisão de funções específicas para os ambientes da assistência à saúde, podemos dizer que o perfil hospital contemporâneo se estabeleceu. 
Podemos destacar, ainda, os estudos de Florence Nightingale, que, a partir da sua experiência na Guerra da Criméia (1853-1856), assentou bases para a construção de Enfermarias com conceitos de ventilação e de distribuição de pacientes, de iluminação e higiene, que são adotadas até hoje por algumas instituições. O estudo da conformação física das enfermarias, chamadas de enfermarias "Nightingale", estabeleceu um novo modelo de espaço para a internação de enfermos, com os exemplos mais marcantes de hospitais concebidos com esta característica. Publicou Notes on Matters Affecting the Health, Efficiency and Hospital Administration of the British Army (1858- Notas sobre a saúde, a eficiência e a administração hospitalar no exército britânico). As enfermarias "Nightingale" serviram de modelo para a implantação de hospitais durante muitos anos, sendo uma referência até as primeiras décadas do século XX, e permanecem sendo usadas, até os dias de hoje, para algumas concepções e desenhos de estruturas com implantação térrea.

A partir daí, até o século $\mathrm{XX}$, as instituições hospitalares sofreram grande incorporação de tecnologia em seus espaços, exigindo no seu planejamento uma acuidade cada vez maior, com instalações, infraestrutura predial sofisticada e, a sempre crescente preocupação em setorizar espaços, separar pacientes com diversas patologias e estabelecer um rígido controle de fluxos e circulações para o desenvolvimento das atividades médicas.

A tendência da verticalização de prédios aparece, já a partir da segunda metade do século XIX, com o surgimento dos "arranha-céus", em Chicago. Na mesma época, observamos o aumento no custo dos terrenos urbanos, a escassez de mão-de-obra de enfermagem, o anseio de reduzir os percursos existentes nos hospitais pavilhonares e, ainda, a questão da inadequação dos longos corredores de circulação ao clima rigoroso da América do Norte. O aprimoramento de tecnologias da construção civil, como o emprego das estruturas metálicas, é a base para o estabelecimento da nova tipologia na construção de hospitais. O uso de elevadores, circulações otimizadas, o emprego de sistemas de ventilação mecânica e facilidades na implantação de infraestrutura predial determinam o desenvolvimento da verticalidade das construções. Surge o hospital monobloco que, mais tarde, se transforma em estruturas de múltiplos blocos verticais, configurando a tipologia marcante do século XX.

Ao lado dos avanços na tecnologia da construção, assistimos a uma grande mudança no modelo de assistência à saúde e do perfil do paciente abrigado nas instituições hospitalares. Podemos citar a continuidade dos trabalhos do cirurgião Lister (século XIX), posteriormente aprofundados por Ernst von Bergman, que estabeleceu bases para a assepsia 
de instrumentos, usadas até hoje. O Centro Cirúrgico hospitalar se reveste de importância, enquanto que os hospitais passam a ser destinados majoritariamente a pacientes que não possuíam recursos para o atendimento domiciliar, usado pelos mais abastados desta época.

No período entre as duas grandes guerras, o hospital monobloco era apenas um empilhamento de enfermarias "Nightingale". A sua anatomia típica destinava o subsolo para os serviços de apoio, o térreo para os consultórios e os serviços de imagem, os primeiros serviços de Raios-X. No primeiro pavimento ficava a administração, nos andares intermediários, a internação e no último pavimento, o então chamado Bloco Operatório.

O modelo de hospital monobloco pode ser visto como um símbolo do triunfo da medicina, pois sua forma enérgica remete aos avanços da pesquisa médica. Esta tipologia modela diversas estruturas hospitalares do século XX e evolui para uma conformação de justaposição de blocos posicionados sobre uma base maior, composta de pavimentos técnicos. O hospital monobloco trabalha a sua estrutura física, com a racionalização das funções de assistência e a setorização de serviços, patologias e complexidade de cuidados, na implantação dos seus pavimentos e prédios. Durante o desenrolar do século XX, os hospitais atingem conformações mistas nas estruturas físicas, com plantas concebidas para a ampliação e a incorporação de novos serviços e usuários, acompanhando o enorme desenvolvimento da ciência médica e o aumento da clientela, agregando populações que, até então, não logravam acesso a estas instituições.

A história da Saúde Pública no Brasil começa, efetivamente, no final do século XIX e início do século XX. No entanto não podemos deixar de citar as Santas Casas de Misericórdia que são as mais típicas instituições brasileiras de assistência à saúde no estabelecimento do país como nação. As Santas Casas chegaram ao Brasil com a vinda dos padres da Companhia de Jesus, no século XVI. A primeira Santa Casa foi fundada em Santos, em 1543, pelo colono Braz Cubas. As Santas Casas têm um papel preponderante na configuração da assistência à saúde, no Brasil e, até hoje, exercem grande influência na prestação de cuidados às populações, com suas instituições, geralmente erguidas em edifícios muito antigos, servindo como objeto de estudo e reflexão para a saúde pública e a arquitetura de ambientes de saúde.

O desenvolvimento da implantação de hospitais brasileiros se confunde com o estabelecimento de ações governamentais de assistência à saúde através da nossa história. Destacamos, aí, as iniciativas de Oswaldo Cruz, buscando a erradicação da peste bubônica, 
febre amarela e varíola, estabelecendo a criação dos mata-mosquitos e a vacinação em massa da população, que culminou na "Revolta da Vacina", no limiar do século XX.

As ações para prover uma rede de assistência adequada à sua demanda continuaram, após a reforma higienista do Prefeito Pereira Passos e do sanitarista Oswaldo Cruz, com a "Reforma Pedro Ernesto". No ano de 1930, com a instalação do Governo Provisório, esboçase a grande transformação que sua administração trouxe para os serviços da saúde pública, no, então, Distrito Federal. Pedro Ernesto formou uma equipe para estudar os problemas de saúde da cidade e empreendeu a construção de diversos Dispensários e Prontos Socorros, promovendo uma grande transformação nas questões de saúde e assistência médicohospitalar, por todo o Rio de Janeiro.

No campo da assistência social, o governo Getúlio Vargas também introduziu importantes mudanças. Ao lado das Caixas de Aposentadoria e Pensões (que vinham desde a década de 1920), foram criados os Institutos de Aposentadoria e Pensões, órgãos controlados pelo Estado responsáveis pela extensão de direitos sociais a categorias nacionais de trabalhadores. Durante a década de 1930, foram criados Institutos de Aposentadoria e Pensões de várias categorias como industriários, comerciários, bancários, funcionários públicos etc. Após 1945, os Institutos de Aposentadoria e Pensões expandiram suas áreas de atuação, que passaram a incluir serviços na área de alimentação, habitação e saúde.

A partir daí tem início um período de construções de grandes edifícios públicos e de outros exemplares com programas bem mais complexos, caracterizando a chamada arquitetura moderna brasileira. Estas estruturas arquitetônicas utilizam os conceitos de modernidade e os pontos preconizados por Le Corbusier, que esteve três vezes no Brasil e se tornou uma referencia para os arquitetos dessa época, para a conformação de projetos hospitalares. Podemos citar exemplos brasileiros destes hospitais como a Maternidade Universitária de São Paulo (1944) de Rino Levi, o Hospital de Clínicas de Porto Alegre (1955) de Jorge Machado Moreira ou o Hospital Sul América, hoje Hospital da Lagoa (1952) de Oscar Niemeyer.

A partir da transferência da Capital Federal para Brasília e da criação do Estado da Guanabara, iniciou-se uma nova fase administrativa, trazendo uma série de novidades para a gestão da rede de saúde do Rio de Janeiro. Em 28 de dezembro de 1962, é criada a SUSEME, através da Lei n ${ }^{\circ} 279$, com a finalidade de gerir a rede hospitalar do Estado da Guanabara. 
Várias obras hospitalares foram iniciadas e construções inacabadas foram finalizadas, como a ampliação do Hospital Miguel Couto, o término das obras de ampliação do Hospital Salgado Filho e o setor de emergência do Hospital Souza Aguiar. A SUSEME procurou abarcar o problema das estruturas físicas da rede de saúde, implantando diversos centros de saúde, que pertencem, atualmente, à rede municipal de assistência, nas mais diversas localidades da cidade.

A partir do golpe militar de 1964, assistimos em nosso país, o fechamento de todos os canais de participação dos trabalhadores nas decisões e nas discussões em torno do sistema previdenciário. Neste panorama, verifica-se a fusão dos IAPs- Institutos de Aposentadorias e Pensões- (exceto o IPASE), através do Decreto $\mathrm{n}^{\circ}$ 72, de 21 de novembro de 1966, que cria o INPS- Instituto Nacional de Previdência Social. Em 1968, o governo elabora o Plano Nacional de Saúde- PNS- que propõe, em síntese, o sistema de livre escolha do médico, pelo cliente, sendo os honorários médicos pagos parte pelo cliente- que exerceu o direito de escolha- e parte pelo sistema da Previdência. Em 1974, é aprovado o Plano de Pronta AçãoPPA- que, entre outras medidas, dispõe sobre a desburocratização e a universalização dos atendimentos às emergências clínicas e cirúrgicas, através da Portaria ${ }^{\circ}$ MPAS 158, de 18 de fevereiro de 1974. O impacto deste plano nas estruturas físicas das unidades da saúde é óbvio, com as instituições sofrendo um grande aumento na demanda por serviços desta natureza.

A rede hospitalar do Rio de Janeiro, cada vez maior e mais onerosa para seus gestores, conforma-se como uma das maiores ofertas de leitos em unidades de saúde, em termos de capacidade instalada. No entanto, a sua estrutura física desarticulada, sucateada e ineficiente, esbarra nos problemas advindos da coexistência das diversas esferas de gestão dos hospitais da cidade: a Federal, com unidades da previdência e do Ministério da Saúde, a Estadual e a Municipal, sem esquecer os hospitais universitários, dos filantrópicos e das unidades da rede conveniada. O período compreendido entre os anos de 1980 a 1983 ficou conhecido como o da crise da previdência social. Independente das diversas e cíclicas crises anteriores, advindas do modelo do seu financiamento, a saúde não conseguia estender a sua cobertura às populações rurais e as críticas ao sistema e a elaboração de novos projetos, buscavam alternativas.

A implantação e a consolidação de um sistema único de saúde dependiam da nova Constituição Federal, aprovada e promulgada em 1988. A concretização dos moldes do novo sistema- o Sistema Único de Saúde (SUS)- foi estabelecida a partir da chamada Lei Orgânica 
da Saúde, a Lei no 8080, de 19 de setembro de 1990. Aí se aponta, de maneira irrefutável, a descentralização dos serviços de assistência à saúde. Suas diretrizes mais fortes, na indicação da municipalização da assistência, encontram-se no seu capítulo III, quando determina o papel de cada uma das esferas de governo para a atuação junto ao Sistema Único de Saúde.

O novo modelo preconizado causa um grande impacto na implantação física dos EAS, exigindo uma nova abordagem, para a arquitetura destas instituições. A busca de uma metodologia para projeto e construção de estabelecimentos de saúde aponta para a necessidade de compatibilização entre a tecnologia médica e de apoio ao diagnóstico e terapia presentes nestas estruturas e a humanização dos seus ambientes, promovendo a integralidade do atendimento à saúde a todos os segmentos da população, como menciona a Lei Orgânica da Saúde.

A tão propalada humanização dos ambientes de saúde requer uma profunda reflexão dos arquitetos na concepção de hospitais que possam oferecer mais do que apenas espaços tecnológicos, agregando às estruturas conceitos de conforto ambiental e sustentabilidade e empregando sistemas e técnicas construtivas que possam oferecer ambientes mais legíveis e acolhedores aos usuários.

\section{BIBLIOGRAFIA CONSULTADA}

ANTUNES, J. L. Hospital: Instituição e História Social. Letras \& Letras. São Paulo, 1991.

CAMPOS, E. S. História e evolução dos hospitais. Ministério da Educação e Saúde, Divisão de Organização Hospitalar. Rio de Janeiro, 1944.

CARDOSO, V. L. A margem da arquitetura grega e romana e princípios geraes modernos de hygiene hospitalar. Rio de Janeiro, Typographia do Anuário do Brasil, 1927 In SANGLARD, G. e COSTA, R. G. R: Direções e traçados da assistência hospitalar no Rio de Janeiro (1923-31). História, Ciências, Saúde - Manguinhos, vol. 11(1): 107-41, Rio de Janeiro, 2004.

CAVAlCANTI, L. Quando o Brasil era Moderno: Guia de Arquitetura 1928-1960. Aeroplano. Rio de Janeiro, 2001.

COSTA, R. G. R.. Hospital do Andaraí (verbete) IN: PORTO, A. et alli. História da saúde no Rio de Janeiro: instituições e patrimônio arquitetônico - Rio de Janeiro (1808-1958). Fiocruz. Rio de Janeiro, 2008.

COSTEIRA, E. M. A. Hospitais de Emergência da Cidade do Rio de Janeiro- uma nova abordagem para a eficiência do ambiente construído. Dissertação (Mestrado). PROARQ/FAU/UFRJ. Rio de Janeiro, 2003.

COSTEIRA, E. M. A.. O hospital do futuro: uma nova abordagem para projetos de ambientes de saúde. In SANTOS, M.; BURSZTYN, I. (orgs.). Saúde e Arquitetura- Caminhos para a humanização dos ambientes hospitalares. SENAC Rio, Rio de Janeiro, 2004. 
KARMAN, J. Manutenção e Segurança Hospitalar Preditivas. IPH. São Paulo, 2011.

MIQUELIN, L. C.. Anatomia dos Edifícios Hospitalares. CEDAS, São Paulo, 1992.

OliVeIRA, J. A e TEIXEIRA, S. M. F. (Im) Previdência Social: 60 Anos de História da Previdência no Brasil. Rio de Janeiro, ABRASCO. Vozes, 1985.

PEVSNER, N. Historia de las Tipologias Arquitectonicas, Gustavo Gilli, Barcelona, 1980.

THOMPSON, J. D. \& GOLDIN, G. The Hospital: A Social and Architectural History. Yale University Press. New Haven and London, 1975. 